\title{
Development of a form rolling micro surface texturing system for friction reduction application in the shaft component
}

X Song, JZ Huang, Sam Oh, Atsushi Danno, Sylvie Castagne

Proceedings of the Institution of Mechanical Engineers, Part C: Journal of Mechanical Engineering Science

Volume: 231 issue: 22 , page(s): 4263-4273

Issue published: November 1, 2017

https://doi.org/10.1177/0954406216661008

\section{ABSTRACT}

Surface texture is one of the most promising methods to achieve friction reduction in the mechanical components, and it has been rapidly developed in the last decade. The friction reduction mechanism of regularly patterned surface texture is widely considered to be lubricant retention and debris entrapment. There are many ways to manufacture micro surface texture, among which deformed-based micro-surface texturing is the least studied. However, it has many unique advantages that cannot be surpassed by the rest, such as high production efficiency, fine geometrical fidelity and smooth surface finishing. Therefore, this study aims at developing a deformationbased low-cost micro form-rolling machine to create micro surface texture on the cylindrical component. A new demonstrator for examining the friction reduction efficiency of the micro surface texture has also been built and tested. Results show that the shaft with micro surface texture is able to reach a maximum of $48.1 \%$ friction reduction at rotation speed $400 \mathrm{r} / \mathrm{min}$ with lubricant SAE30 compared to the nontextured workpiece with the same condition. 